\title{
ANALISIS SEBARAN KARBON MONOKSIDA DARI SUMBER TRANSPORTASI DARI JALAN SISINGAMANGARAJA DENGAN METODE FINITE LENGTH LINE SOURCE BERBASIS SISTEM INFORMASI GEOGRAFIS
}

\author{
ANALYSIS OF CARBON MONOXIDE DISPERSION FROM \\ TRANSPORTATION AT SISINGAMANGARAJA STREET USING \\ FINITE LENGTH LINE SOURCE METHOD SUPPORTED BY \\ GEOGRAPHIC INFORMATION SYSTEM
}

\author{
Deni Gusrianti ${ }^{1}$, Ahmad Perwira Mulia Tarigan ${ }^{2}$, Isra' Suryati $^{3}$ \\ ${ }^{1,3}$ Program Studi Teknik Lingkungan, Fakultas Teknik, Univesitas Sumatera Utara \\ Jalan Alumni Kampus USU, Medan 20155 \\ ${ }^{2}$ Departemen Teknik Sipil, Fakultas Teknik, Universitas Sumatera Utara \\ Jalan Perpustakaan Kampus USU, Medan 20155 \\ Email: denigusrianti@gmail.com
}

\begin{abstract}
ABSTRAK
Penelitian ini bertujuan untuk mengetahui pola sebaran karbon monoksida (CO)dari Jalan Sisingamangarajadengan metode Finite Length Line Source (FLLS) dan memetakan sebaran dengan aplikasi SIG. Berdasarkan hasil pengamatan volume lalu lintas, total jumlah kendaraan adalah 7.591 unit/jam (pagi) dan 7.433 unit/jam (siang). Jumlah kendaraan tersebut menyumbangkan laju emisi sebesar 49.171,7 $\mu \mathrm{g} / \mathrm{m}$.s pada pagi hari dan pada siang hari sebesar 46.943,1 $\mu \mathrm{g} / \mathrm{m} . \mathrm{s}$. Bedasarkan perhitungan dengan FLLS konsentrasi CO paling tinggi adalah pada tepi jalan (roadside) yaitu sebesar $20.340 \mu \mathrm{g} / \mathrm{Nm}^{3}$ pada pagi hari dan $18.340 \mu \mathrm{g} / \mathrm{Nm}^{3}$ pada siang hari. Analisa spasial dengan Sistem Informasi Geografis menghasilkan wilayah sebaran dampak dari sumber tersebut adalah Kelurahan Harjosari 2. Perbandingan hasil pemodelan dan hasil pengukuran di lapangan dengan wilmott's index menghasilkan nilai $d=0,69-0,84, R=0,93-0,96$, dan NMSE=0,02-0,04. Hasil validasi memiliki keakuratan 16,5\%-17\%.Kisaran ini masih dalam kriteria pemodelan Gaussian (10\%- 20\%).
\end{abstract}

Keyword: CO, finite length line source, SIG, transportasi

\section{ABSTRACT}

Purpose of this study is to determine the distribution pattern of carbon monoxide (CO) from Singamangaraja street by using Finite Length Line Source (FLLS) method and map to the distribution with GIS aplication. Based on the results of observations of traffic volume on the Singamangaraja street is 7.591 units/hour (morning) and 7.433 units/hour (noon). The amount emission rate is $49.171 .7 \mu \mathrm{g} / \mathrm{m} . \mathrm{s}$ in the morning and $46.943 .1 \mu \mathrm{g} / \mathrm{m} . \mathrm{s}$ in the noon. According to calculations FLLS the highest CO concentration is at roadside $\left(20.340 \mu \mathrm{g} / \mathrm{Nm}^{3}\right.$ in the morning and $18.340 \mu \mathrm{g} / \mathrm{Nm} 3$ in the noon). Based on direct measurement of the concentration of a maximum of $18.323 \mu \mathrm{g} / \mathrm{Nm}^{3}$ in the morning and $17.177 \mu \mathrm{g} / \mathrm{Nm}^{3}$ at noon. Spatial analysis with Geographic Information System generate distribution impact area of the source was Harjosari 2 district. Comparison between modeling and field survey using wilmott's index method had d=0,69-0,84, $R=0,93-0,96$, dan NMSE=0,02-0,04. Statistic validation had 16,5\%-17\% accuracy and still in range of Gaussian criteria (10\%-20\%). 


\section{PENDAHULUAN}

Tansportasi darat/kendaraan bermotor merupakan salah satu sumber emisi pencemar udara (KLH, 1999; Soedomo, 1999; Peavy dkk, 1985). Zat pencemar spesifik dari sumber transportasi darat adalah $\mathrm{CO}$ (Soedomo, 1999). Gas ini berbahaya bagi manusia karena kemampuannya mengikat hemoglobin dalam darah 140-300 kali lebih kuat daripada kemampuan oksigen (Wardhana, 2004). Penelitian ini dilakukan di Jalan Sisingamangaraja yang merupakan salah satu titik kepadatan lalu lintas di Kota Medan. Jalanini merupakan jalan arteri primer di Kota Medan yang menghubungkan Kota Medan dengan kabupaten atau kota lainnya dalam Provinsi Sumatera Utara. Volume lalu lintas pada jam sibuk di Jalan $\begin{array}{lll}\text { Sisingamangaraja adalah } \quad 8.208 & \end{array}$ kendaraan/jam, dengan V/C Ratio 0,61 (DISHUB Kota Medan, 2016) Padatnyajumlahkendaraan yang melewati area inimengakibatkanbanyakpolutanCO yang diemisikan ke udara ambien. Apabila tidak ditangani dengan baik akan menimbulkan dampak negatif bagi lingkungan terutama bagi kesehatan manusia.

Penelitian ini bertujuan untuk mengestimasi emisi dari kendaraan bermotor di Jalan Sisingamangaraja, mengetahui pola sebaran $\mathrm{CO}$ menggunakan metodefinite length line source(FLLS), memetakan sebaran $\mathrm{CO}$ dengan aplikasi SIG, dan membandingkan hasil pemodelan dengan pemantauan langsung dilapangan.Persebaran pencemaran udara dipengaruhi oleh faktor meteorologis seperti arah dan kecepatan angin dan stabilitas atmosfer (KLH, 1999; Nevers, 2000).

Line source gaussian model adalah pengembangan dari model gaussian plume dengan mengasumsikan bahwa line source adalah sebuah deret point source, yang saling tergantung (mutually dependent), yang masing-masing menghasilkan kepulan polutan. Dengan demikian, konsentrasi suatu titik di sisi jalan dihitung sebagai jumlah dari deret konsentrasi titik-titik tersebut (Paramitadevi, 2014).

Penelitian terdahulu (Jarrot dkk, 2005; Hoek dkk, 2008; Hamid dkk 2015; Suryati dan
Khair, 2016) menjelaskan bahwa pemodelan distribusi spasial dari polutan dapat membantu untuk memperkirakan konsentrasi polutan di daerah yang tidak mempunyai stasiun pemantauan pencemaran udara, juga dapat menentukan daerah yang melebihi standar polusi udara. Selanjutnya, pemodelan spasial distribusi polutan dapat dimanfaatkan untuk penilaian eksposur dan studi epidemiologi.

Mengintegrasikan model dengan SIG menghasilkan sebuah dimensi geografis pada informasi kualitas udara dengan menghubungkan konsentrasi pencemaran sebenarnya kepada lingkungan dan kehidupan manusia pada lokasi tersebut. Tools analisa numeris SIG dapat mendemonstrasikan hubungan antara kualitas udara yang buruk dengan kesehatan masyarakat dan kesehatan lingkungan (Yerramilli dkk, 2011).

\section{METODE PENELITIAN}

\section{Pengumpulan data}

Data yang diperlukan adalah volume lalu lintas, faktor emisi, arah dan kecepatan angin, intensitas penyinaran matahari, peta Kota Medan, serta konsentrasi CO hasil pengukuran langsung dilapangan. Volume lalu lintas didapatkan dari pengamatan langsung dilapangan menggunakan manual counter. Jenis kendaraan yang dihitung adalah sepeda motor, mobil penumpang, bus, dan truk. Faktor emisi didapatkan dari faktor emisi nasional (KLH, 2013). Arah dan kecepatan angin didapatkan dari BMKG Wilayah 1 Medan, peta Kota Medan didapatkan dari BAPPEDA Provinsi Sumatera Utara. Sedangkan konsentrasi CO didapatkan dengan melakukan pengukuran langsung dilapangan menggunakan metode NDIR Analyzer (BSN, 2011).

Perhitungan volume lalu lintas dan pengukuran konsentrasi $\mathrm{CO}$ dilapangan dilakukan pada hari Sabtu, tanggal 15 Oktober 2016. Sampling dilakukan selama 1 (satu) jam untuk pengamatan pagi dan 1 (satu) jam untuk pengamatan siang. Lokasi pengukuran $\mathrm{CO}$ di lapangan adalah pada tepi jalan (roadside), pada jarak $300 \mathrm{~m}, 500 \mathrm{~m}$, dan $600 \mathrm{~m}$ ke arah selatan. 


\section{Pengolahan Data}

Data volume lalu lintas dikalikan dengan faktor emisi untuk mendapatkan laju emisi. Kemudian dimasukkan ke dalam persamaan FLLS seperti dibawah ini (Paramitadevi, 2014; Cooper \& Alley, 1994):

$$
\mathrm{C}=\frac{\mathrm{K}}{\sqrt{2 \pi}}\left(\mathrm{G}_{2}-\mathrm{G}_{1}\right)
$$

$\mathrm{K}=\frac{\mathrm{q}}{\mathrm{u} \sigma_{\mathrm{z}}}\left\{\exp \left[-\frac{(\mathrm{z}-\mathrm{H})^{\mathrm{z}}}{2 \sigma_{\mathrm{Z}}^{\mathrm{z}}}\right]+\exp \left[-\frac{(\mathrm{z}+\mathrm{H})^{\mathrm{z}}}{2 \sigma_{\mathrm{Z}}^{\mathrm{z}}}\right]\right\}^{2}$

$\mathrm{G}_{2}-\mathrm{G}_{1}=\int_{\mathrm{B} 1 \sqrt{\sqrt{2 \pi}}}^{\mathrm{B}} \frac{1}{\exp }\left(\frac{-\mathrm{B}^{\mathrm{Z}}}{2}\right) \mathrm{dB}^{2}$ 3

$B_{2}=\frac{y_{2}}{\sigma_{y}} ; B_{1}=\frac{y_{1}}{\sigma_{y}}$

Keterangan :

$\mathrm{C}:$ Konsentrasi $\left(\mu \mathrm{g} / \mathrm{Nm}^{3}\right)$

$\mathrm{Q}$ : Laju emisi sumber polutan gram.m/detik

$\overline{\mathrm{u}}$ : Kecepatan angin pada posisi $\mathrm{x}(\mathrm{m} /$ detik)

$\sigma_{\mathrm{z}}$ : Parameter dispersi konstanta pada posisi z (m)

$\sigma_{\mathrm{y}}$ : Parameter dispersi konstanta pada posisi y (m)

$\mathrm{z}$ : Posisi arah z pada koordinat kartesius (m)

$\mathrm{H}$ : Ketinggian efektif sumber emisi (m)

$\mathrm{B}:$ Rasio panjang ruas jalan terhadap parameter dispersi $\sigma_{\mathrm{y}}$

Validasi yang digunakan dalam membandingkan hasil perhitungan dengan pengukuran langsung dilapangan mengacu pada (Paramitadevi, 2014; Willmott dkk,
2012; Hassan dkk, 2006).Terdiri dari Wilmott's Index of Agreement (d), Normalized Mean Square Error (NMSE), Korelasi Pearson (R), Friction Bias (FB), dan Factor of $2\left(\mathrm{Fa}_{2}\right)$. Hasil penelitian dapat diterima apabila:

1. NMSE dalam kisaran 0,5

2. FB dalam rentang -2 sampai dengan 2

3. Nilai $\mathrm{R}$ dan $\mathrm{d}$ mendekati 1

4. $\mathrm{Fa}_{2}$ sekitar $50 \%$.

Data konsentrasi yang didapatkan baik dari perhitungan maupun dari pengukuran langsung dilapangan ditumpang-tindihkan dengan peta Kota Medan untuk mendapatkan kondisi spasial penyebaran $\mathrm{CO}$.

\section{HASIL DAN PEMBAHASAN}

\section{Volume Lalu Lintas Dan Persentase Laju Emisi}

Jalan Sisingamangaraja merupakan jalan yang menghubungkan Kota Medan dengan kota lainnya di Provinsi Sumatera Utara dan berstatus jalan nasional sehingga mengakibatkan lalu lintas di jalan ini relatif padat. Total jumlah kendaraan yang melintas pada waktu pagi adalah sebanyak 7.591 unit/jam, dan total jumlah kendaraan yang melintas pada waktu siang adalah 7.433 unit/jam, jumlah tersebut tidak jauh berbeda dengan data volume lalu lintas Jalan Sisingamangaraja yang didapatkan dari Dishub Kota Medan yaitu sebanyak 8.208 kendaraan/jam. Persentase laju emisi yang disumbangkan untuk masing-masing waktu pengukuran dapat dilihat pada Gambar 1 dan Gambar 2.

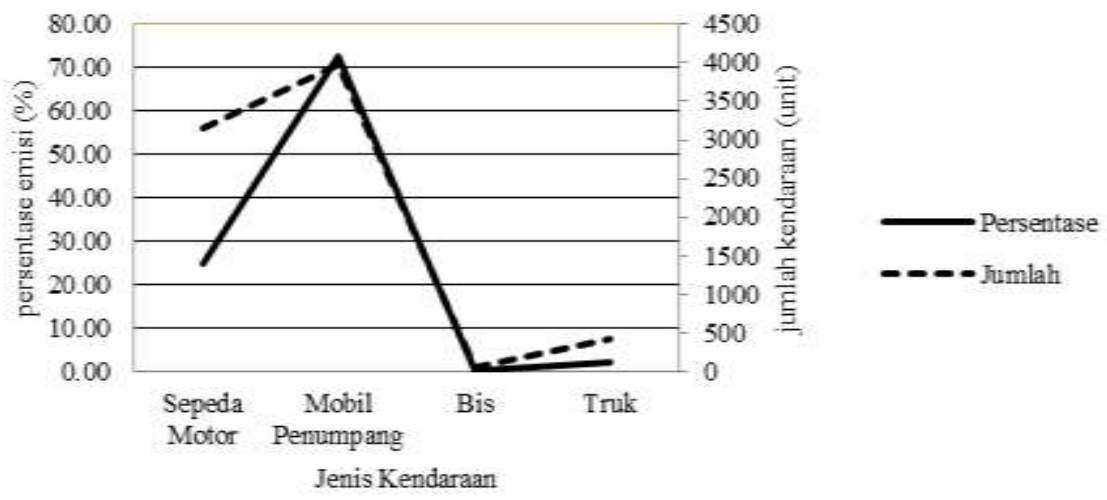

Gambar 1. Persentase Laju Emisi dari Kendaraan Pagi Hari 


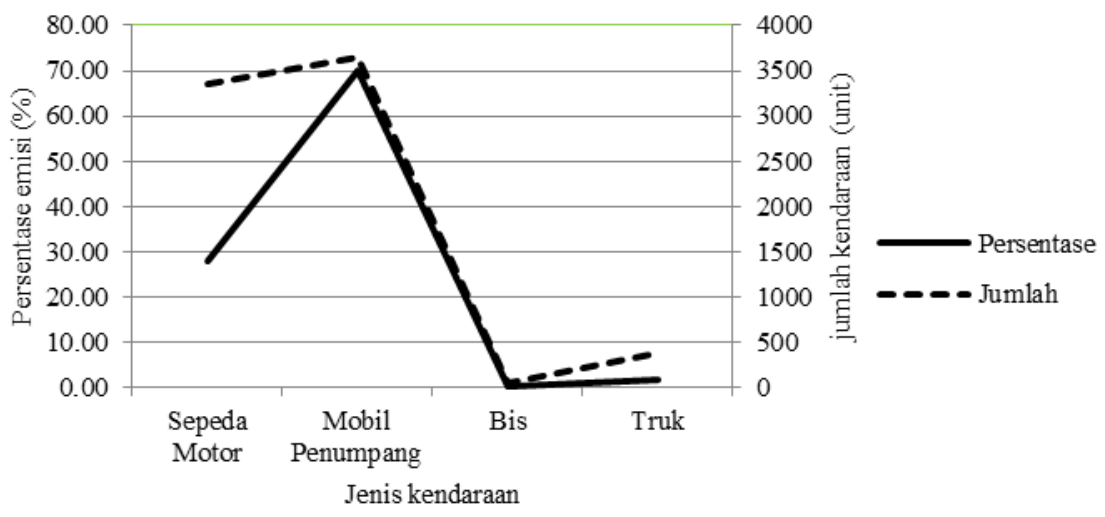

\section{Gambar 2. Persentase Laju Emisi dari Kendaraan Siang Hari}

Banyaknya jumlah kendaraan penumpang pribadi seperti mobil, sepeda motor, yang melewati jalan ini dikarenakan adanya aktivitas warga di sekitar Kecamatan Medan Amplas untuk menuju dan kembali dari pusat kota. Bus yang melewati jalan ini adalah bus antar provinsi dan bus Bandara Kuala Namu. Jumlah bus yang melewati jalan ini dipengaruhi oleh aktivitas masyarakat Kota Medan pulang dan pergi ke luar kota. Sedangkan kendaaraan pengangkut barang seperti truk juga banyak melintasi jalan ini dikarenakan banyaknya transfer barang masuk dan keluar kota Medan.Variasi jumlah emisi yang disumbangkan oleh setiap jenis kendaraan dipengaruhi oleh variasi jumlah dan faktor emisi.

\section{Distribusi Angin dan Stabilitas Atmosfer}

Distribusi angin yang diperhitungkan dalam penelitan ini adalah arah dan kecepatan angin dominan yang di gambarkan dengan windrose. Data yang digunakan adalah data arah dan kecepatan angin rata-rata bulanan tahun 2011-2015 dari stasiun Balai Besar Meteorologi Klimatologi dan Geofisika (BMKG) Wilayah 1 Medan.Diagram windrose dapat dilihat pada Gambar 3. Dari Gambar dapat dilihat arah angin dominan dari arah utara $\left(0^{\circ}\right)$ dan arah timur $\left(90^{\circ}\right)$ dengan kecepatan angin rata-rata adalah 2,25 $\mathrm{m} / \mathrm{s}$.

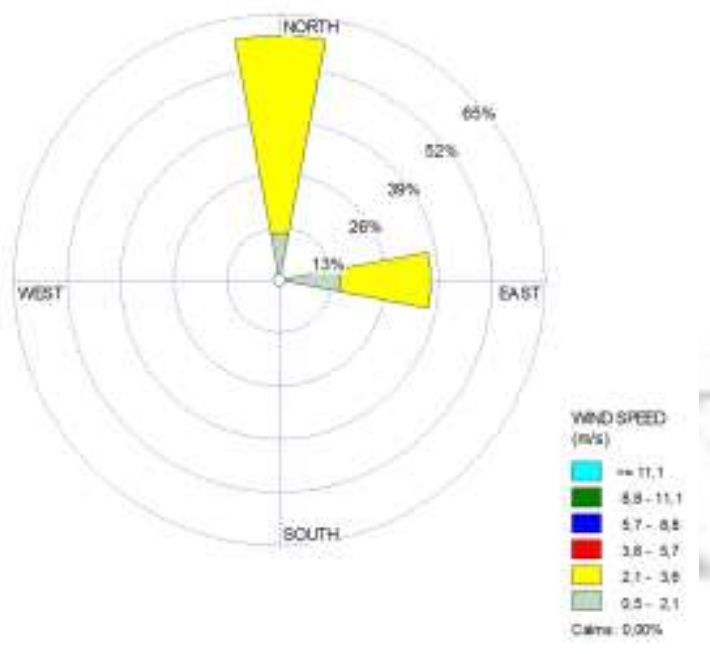

Gambar 3. Windrose

Sumber Data: BMKG, 2011-2015 (data telah diolah)

Stabilitas atmosfer dipengaruhi oleh radiasi matahari dan kecepatan angin. Berdasarkan data kecepatan angin dan penyinaran matahari tahun 2011-2015 yang didapatkan dari Balai Besar Meteorologi Klimatologi dan Geofisika (BMKG) Wilayah 1 Medan yang kemudian dibandingkan dengan tabel kelas stabilitas atmosfer Pasquill. Persentase stabilitas atmosfer dapat dilihat pada Gambar 4. 


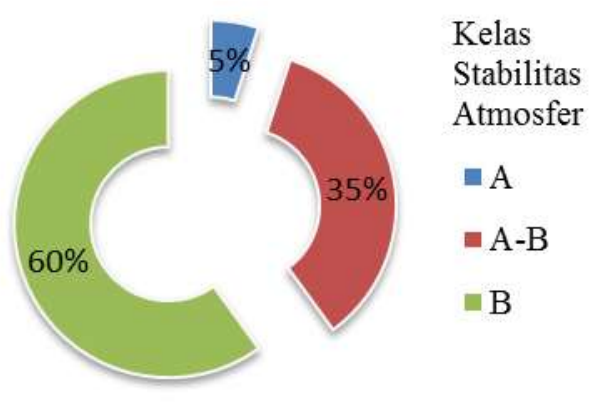

Gambar 4. Persentase Kelas Stabilitas Atmosfer

Sumber Data: BMKG, 2011-2015 (data telah diolah)

Dari Gambar 4 dapat dilihat kelas stabilitas atmosfer didominasi oleh kelas B sebanyak $60 \%$, A-B sebanyak $35 \%$, dan A sebanyak $5 \%$. Berdasarkan hal tersebut maka kelas stabilitas yang akan digunakan untuk perhitungan lebih lanjut adalah kelas B.

Menurut Pasquill (1974) dalam Supriyadi (2009), pada kelas kestabilan B massa udara akan cenderung turun karena suhu udara lebih rendah dibandingkan suhu di atmosfer yang mengakibatkan kadar polutan per satuan volume menjadi lebih besar.

\section{Analisis Hasil Pemodelan Finite Length Line Source (FLLS)}

Perhitungan dengan metode finite length line source menggunakan Persamaan 1 sampai Persamaan 4. Dalam penelitian ini dihitung konsentrasi pada jarak $\pm 7 \mathrm{~m}$ dari sumber sampai $\pm 2000 \mathrm{~m}$ dari sumber. Hasil konsentrasi untuk jarak 7 meter sampai $2.000 \mathrm{~m}$ dari sumber emisi dapat dilihat pada Gambar 5 dan 6 di bawah ini.

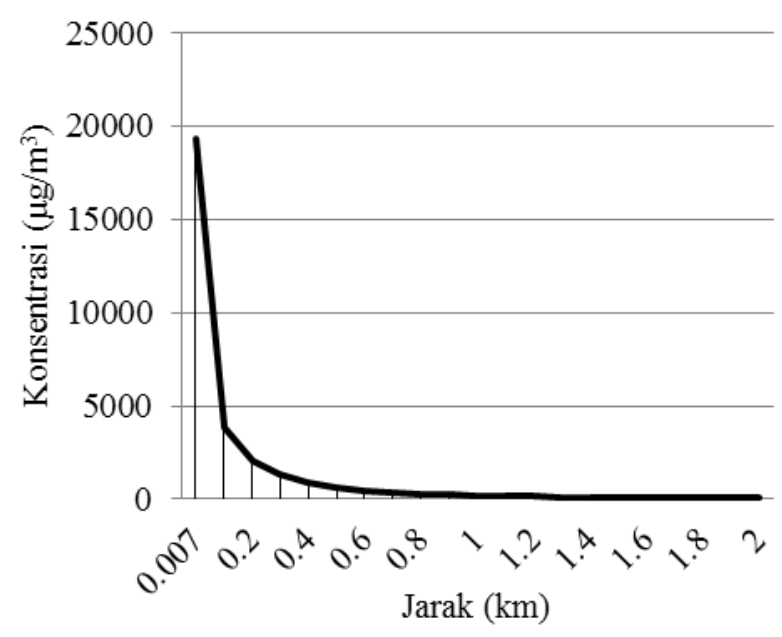

Gambar 5. Konsentrasi CO Hasil Pemodelan FLLS Pagi

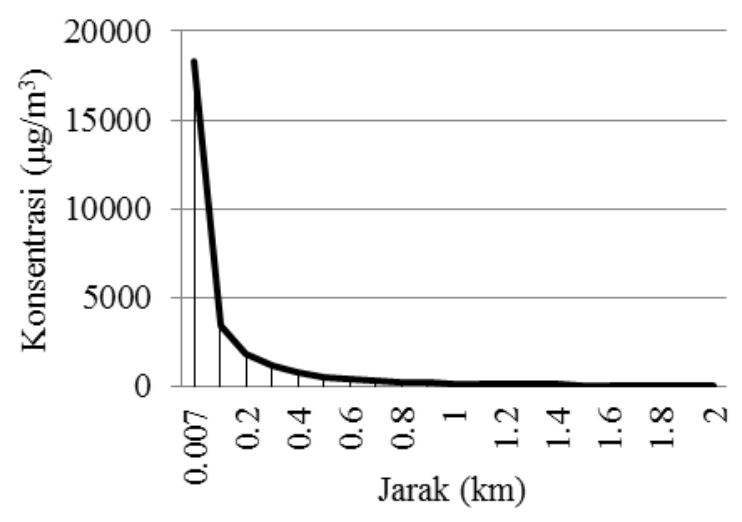

\section{Gambar 6. Konsentrasi CO Hasil Pemodelan FLLS Siang}

Berdasarkan Gambar 5 dan Gambar 6 semakin jauh jarak dari sumber maka konsentrasi pencemar semakin menurun. Hal ini membuktikan bahwa jarak mempengaruhi persebaran polutan. Konsentrasi tertinggi pada pagi hari adalah pada jarak 0,007 km atau $7 \mathrm{~m}$ dari sumber emisi yaitu sebanyak $20.340 \mu \mathrm{g} / \mathrm{Nm}^{3}$. Sedangkan di waktu siang dengan jarak yang sama konsentrasi CO adalah sebanyak $18.340 \mu \mathrm{g} / \mathrm{Nm}^{3}$. Pada waktu pagi konsentrasi terendah adalah pada $2 \mathrm{~km}$ atau $2.000 \mathrm{~m}$ dari sumber dengan konsentrasi sebanyak $49,497 \mu \mathrm{g} / \mathrm{Nm}^{3}$ dan pada pagi hari dan $44,629 \mu \mathrm{g} / \mathrm{Nm}^{3}$ pada siang hari.

Pada pengukuran pagi hari cuaca cerah dan kecepatan angin adalah 2,45 $\mathrm{m} /$ detik. Sedangkan pada saat pengukuran siang cuaca lebih cerah dengan kecepatan angin lebih tinggi yaitu 2,58 $\mathrm{m} /$ detik. Cuaca semakin 
cerah mengindikasikan intensitas penyinaran matahari yang semakin besar. Berdasarkan tabel Pasquill, kondisi atmosfer pada pagi hari di kelas B, dan kondisi atmosfer pada siang hari di kelas A-B. Hal ini berarti kondisi atmosfer pada pagi hari lebih stabil dibandingkan siang hari. Ketika keadaan atmosfer lebih stabil maka udara akan cenderung bergerak ke bawah dan memperlambat proses dispersi sehingga konsentrasi polutan pada permukaan bumi lebih besar. Hal tersebut yang mengakibatkan konsentrasi pada pagi hari lebih besar dibandingkan konsentrasi pada siang hari.

\section{Perbandingan Konsentrasi Hasil Perhitungan, Pengukuran di Lapangan dan Baku Mutu}

Gambar 7dan 8menunjukkan perbandingan konsentrasi $\mathrm{CO}$ hasil pemodelan, konsentrasi $\mathrm{CO}$ hasil pengukuran dan baku mutu kualitas udara ambien nasional menurut Lampiran Peraturan Pemerintah Nomor 41 Tahun 1999 Baku Mutu Udara Ambien Nasional(KLH, 1999).

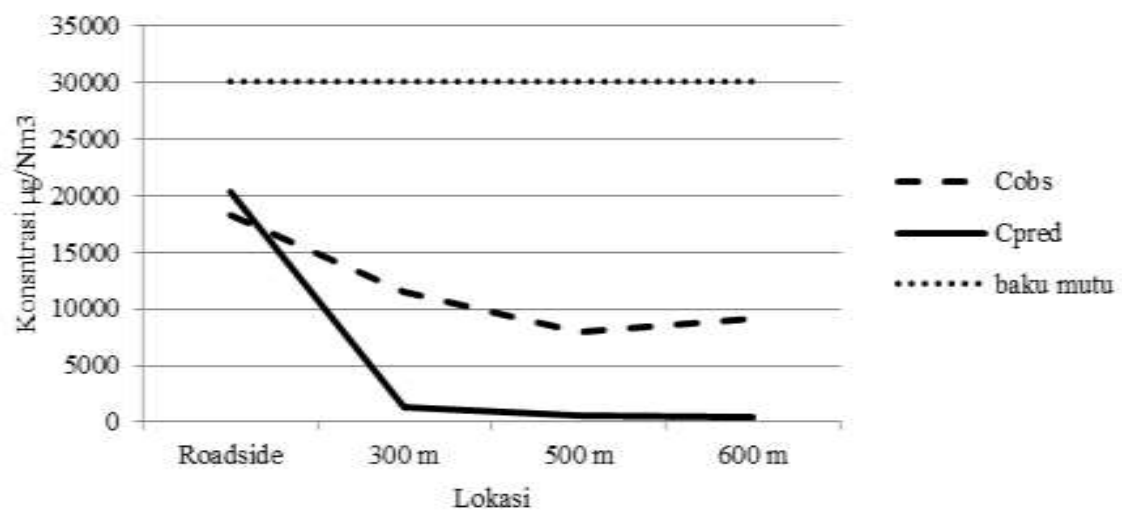

Gambar 7. Perbandingan Konsentrasi CO Hasil Perhitungan, Hasil Pengukuran, dan Baku Mutu Hasil Pengukuran Pagi

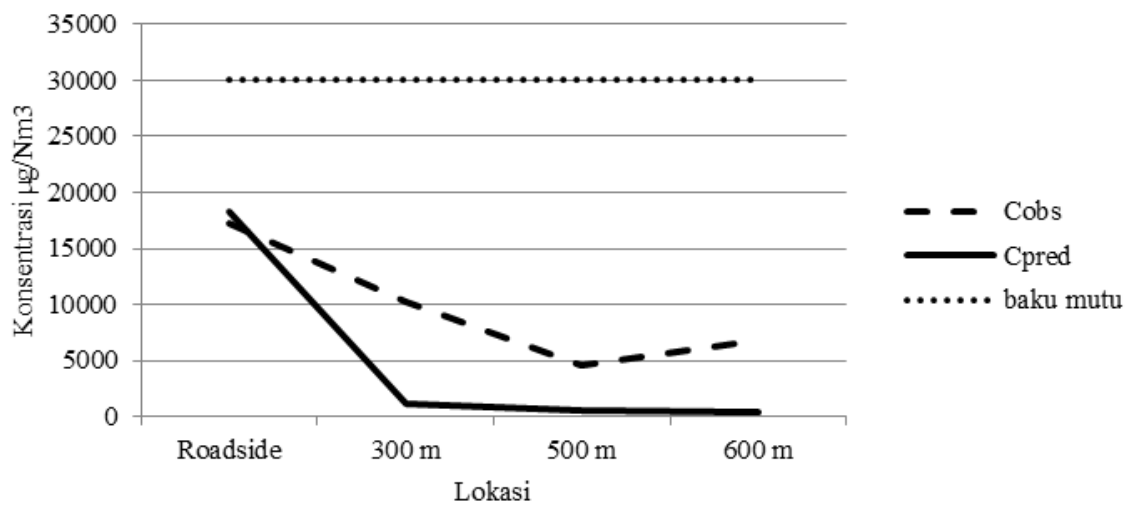

\section{Gambar 8. Perbandingan Konsentrasi CO Hasil Perhitungan, Hasil Pengukuran, dan Baku Mutu Hasil Pengukuran Siang}

Berdasarkan hasil pemodelan, semakin jauh jarak dari sumber maka konsentrasi CO semakin menurun. Hal ini membuktikan bahwa jarak mempengaruhi persebaran polutan. Konsentrasi tertinggi pada pagi hari adalah pada jarak $7 \mathrm{~m}$ dari sumber emisi yaitu sebanyak $20.340 \mu \mathrm{g} / \mathrm{Nm}^{3}$. Sedangkan di waktu siang dengan jarak yang sama konsentrasi CO adalah sebanyak 18.340 $\mu \mathrm{g} / \mathrm{Nm}^{3}$. Pada waktu pagi konsentrasi terendah adalah pada $\pm 2.000 \mathrm{~m}$ dari sumber dengan konsentrasi sebanyak $49,497 \mu \mathrm{g} / \mathrm{Nm}^{3}$ 
dan pada pagi hari dan $44,629 \mu \mathrm{g} / \mathrm{Nm}^{3}$ pada siang hari.

Pada pengukuran pagi hari cuaca cerah dan kecepatan angin adalah 2,45 $\mathrm{m} /$ detik. Sedangkan pada saat pengukuran siang cuaca lebih cerah dengan kecepatan angin lebih tinggi yaitu $2,58 \mathrm{~m} /$ detik. Cuaca semakin cerah mengindikasikan intensitas penyinaran matahari yang semakin besar. Kondisi atmosfer pada siang hari di kelas A-B. Hal ini berarti kondisi atmosfer pada pagi hari lebih stabil dibandingkan siang hari. Ketika keadaan atmosfer lebih stabil maka udara akan cenderung bergerak kebawah dan memperlambat proses dispersi sehingga konsentrasi polutan pada permukaan bumi lebih besar. Hal tersebut yang mengakibatkan konsentrasi pada pagi hari lebih besar dibandingkan konsentrasi pada siang hari.
Konsentrasi CO hasil pengukuran masih berada dibawah baku mutu udara ambien PP Nomor 41 tahun 1999. Konsentrasi CO tertinggi yaitu padaroadside untuk sampling pagi hari sebesar $18.323 \mu \mathrm{g} / \mathrm{Nm}^{3}$ dan 17.177 $\mu \mathrm{g} / \mathrm{Nm}^{3}$ untuk sampling siang hari. Pada lokasi berikutnya konsentrasi CO cenderung turun di karenakan karena jaraknya dari sumber emisi semakin jauh. Namun pada titik $600 \mathrm{~m}$ konsentrasi $\mathrm{CO}$ cenderung naik dikarenakan adanya pengaruh sumber emisi lain berupa sumber transportasi. pengukuran pada titik $600 \mathrm{~m}$ dilakukan berdekatan dengan jalan pada komplek perumahan warga.

Validasi hasil pemodelan $\mathrm{CO}$ dengan hasil pengukuran di lapangan dapat dilihat pada Tabel 1 dan Tabel 2 dibawah ini.

Tabel 1 Validasi Statistik Hasil Pemodelan CO Pagi

\begin{tabular}{llrlllllc}
\hline NO & Lokasi Penelitian & Cobs & Cpred & $\mathbf{d}^{\mathbf{a}}$ & $\mathbf{N M S E}^{\mathbf{b}}$ & $\mathbf{R}^{\mathbf{c}}$ & $\mathbf{F B}^{\mathbf{d}}$ & $\mathbf{F a}_{2}{ }^{\mathbf{e}} \mathbf{( \% )}$ \\
\hline $\mathbf{1}$ & Roadside & 18323,11 & 20340,75 & & & & & \\
$\mathbf{2}$ & $300 \mathrm{~m}$ & 11451,94 & 1293,501 & & & & & \\
$\mathbf{3}$ & $500 \mathrm{~m}$ & 8016,36 & 616,1519 & 0,69 & 0,04 & 0,96 & $-1,02$ & 33 \\
$\mathbf{4}$ & $600 \mathrm{~m}$ & 9161,554 & 454,0679 & & & & & \\
& Rata-Rata & 11738,24 & 5676,118 & & & & & \\
& Standar Deviasi & 3997,942 & 8472,483 & & & & & \\
\hline
\end{tabular}

Sumber: Survey dan Analisa, 2016

Keterangan:

a. Willmot's index of agreement

b. Normalize Mean Square Error

c. Koefisien korelasi pearson d. Fraction Bias

e. Persentase dalam rentang $0,5 \leq$ Cobs/Cpred $\leq 2$

Tabel 2 Validasi Statistik Hasil Pemodelan CO Siang

\begin{tabular}{ccccccccc}
\hline NO & Lokasi Penelitian & Cobs & Cpred & $\mathbf{d}^{\mathbf{a}}$ & $\mathbf{N M S E}^{\mathbf{b}}$ & $\mathbf{R}^{\mathbf{c}}$ & $\mathbf{F B}^{\mathbf{d}}$ & $\mathbf{F a}_{\mathbf{2}}{ }^{\mathbf{e}} \mathbf{( \% )}$ \\
\hline $\mathbf{1}$ & Roadside & 17177,91 & 18340,031 & & & & & \\
$\mathbf{2}$ & $300 \mathrm{~m}$ & 10306,75 & 1166,272 & & & & & \\
$\mathbf{3}$ & $500 \mathrm{~m}$ & 4580,777 & 555,547 & 0,84 & 0,02 & 0,93 & $-1,41$ & 34 \\
$\mathbf{4}$ & $600 \mathrm{~m}$ & 6871,166 & 409,4057 & & & & & \\
& Rata-Rata & 9734,151 & 5117,814 & & & & & \\
& Standar Deviasi & 4756,349 & 7639,127 & & & & & \\
\hline
\end{tabular}

Sumber : Survey dan Analisa, 2016

Keterangan :

a. Willmot's index of agreement

b. Normalize Mean Square Error

c. Koefisien korelasi pearson

d. Fraction Bias

e. Persentase dalam rentang $0,5 \leq$

Cobs/Cpred $\leq 2$

Berdasarkan Tabel 1 dan 2 dapat dilihat

0,69 dan untuk pengukuran siang adalah

bahwa nilai d untuk pengukuran pagi adalah

0,84 . Nilai d mendekati 1 menunjukkan 
tingginya tingkat kesesuaian antara hasil pemodelan dengan pengukuran di lapangan. Nilai NMSE kurang dari 0,5 dan Fa2 kurang dari $50 \%$ untuk pengukuran pagi dan siang menandakan nilai eror dan bias pada data kecil dari 0,5. Nilai $R$ mendekati 1 menunjukkan hasil pemodelan memiliki hubungan linear dengan hasil pengukuran. Nilai FB sebesar -1,41 dan -1,02 masih dalam rentang yang diperbolehkan.

Menurut (Paramitadevi, 2014; Heist dkk, 2013; Schenelle, 2003) formula kepulan Gaussian untuk sumber emisi di permukaan apabila dibandingkan dengan hasil observasi memiliki tingkat keakuratan sebesar 10\%20\%. Berdasarkan $50 \% \quad \mathrm{Fa}_{2}$ keakuratan penelitian ini adalah sebesar 16,5\%-17\% dan masih dalam rentang kriteria tersebut.

Hubungan linear antara hasil pemodelan dengan pegukuran dilapangan dibuktikan oleh Gambar 7 dan 8 yang menunjukkan bahwa tren konsentrasi hasil perhitungan dan hasil pengukuran langsung dilapangan adalah sama untuk titik sampling roadside, $300 \mathrm{~m}$ dari jalan dan $500 \mathrm{~m}$ dari jalan. Hasil tersebut membuktikan adanya kesesuaian antara hasil perhitungan dan pengukuran langsung dilapangan yang juga dibuktikan oleh nilai koefisien korelasi Pearson (R) sangat mendekati 1.

\section{Analisa Spasial dengan Aplikasi Sistem Informasi Geografis}

Gambar 9 sampai Gambar 12 menunjukkan hasil analisa spasial menggunakan Sistem
Informasi Geografis. Wilayah yang terkena dampak sebaran $\mathrm{CO}$ adalah Kelurahan Harjosari 2 sampai pada daerah perbatasan Kabupaten Deli Serdang. Berdasarkan hasil perhitungan, konsentrasi maksimal berada pada wilayah yang dekat dengan jalan dan semakin jauh jarak dari sumber konsentrasi akan semakin kecil, sedangkan berdasarkan hasil pengukuran konsentrasi maksimal juga berada pada wilayah yang dekat dengan jalan, namun pada jarak 600 meter konsentrasi CO lebih besar dari pada jarak 500 meter.

Menurut data dari BPS Kota Medan (2015) jumlah penduduk Kecamatan Medan Amplas adalah 121. 362 orang dengan luas wilayah $11,19 \mathrm{~km}^{2}$ dan rasio kepadatan 10.846 penduduk per $\mathrm{km}^{2}$. Dampak $\mathrm{CO}$ bagi manusia adalah terjadinya ikatan antara $\mathrm{CO}$ dan hemoglobin membentuk $\mathrm{COHb}$, gejala yang langsung dirasakan penduduk adalah berupa penyakit ISPA dan gangguan paruparu. Jumlah kejadian penyakit Data dari BPS Kota Medan (2015) menyebutkan ISPA ringan di Kecamatan Medan Amplas adalah sebanyak 15.209, bronchitis sebanyak 276. Hubungan antara kejadian penyakit dan sebaran CO perlu dikaji lebih lanjut. Menurut (Paramitadevi, 2014; Handa dan Tai, 2005) di Indonesia jarang dilakukan pemeriksaan terhadap $\mathrm{HbCO}$ pada pasien, sehingga mengakibatkan gejala ini diketahui setelah pasien dalam kondisi akut saat dibawa ke pusat pelayanan kesehatan.

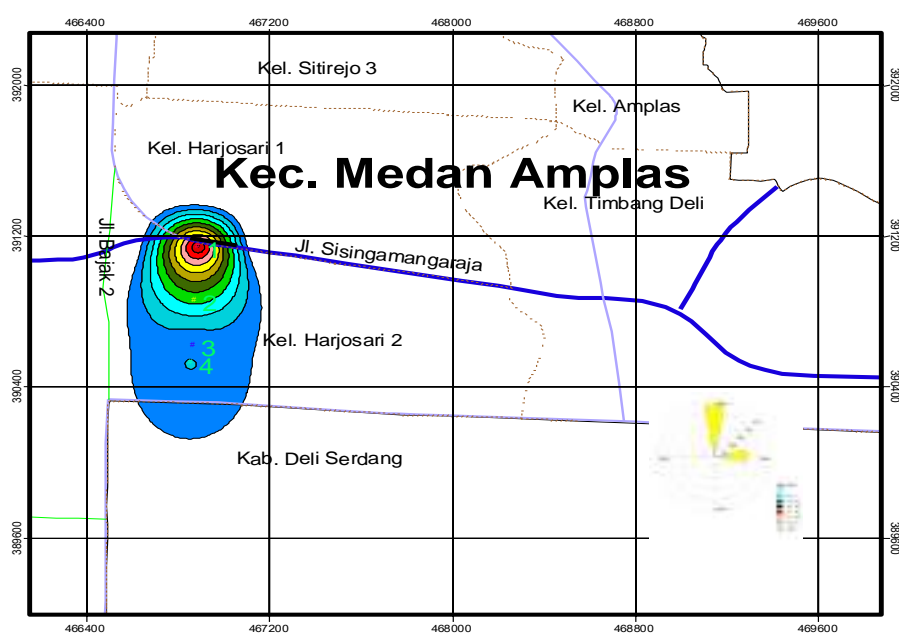

Gambar 9. Isoplet Konsentrasi Hasil Pengukuran Pagi
Lokasi Sampling 1 Roadside $2300 \mathrm{~m}$ dari jalan $4600 \mathrm{~m}$ dari jalan segmen jalan segmen jalan
yang diamati Batas kelurahan jalan lokal primer jalan arteri sekunder Njalan arteri prim Konsentrasi (ug/Nm $18001-19000$ $17001-18000$ $16001-17000$
$15001-16000$
$14001-15000$ $13001-14000$ $12001-13000$ $11001-12000$ $10001-11000$ $9001-10000$
$8000-9000$ 


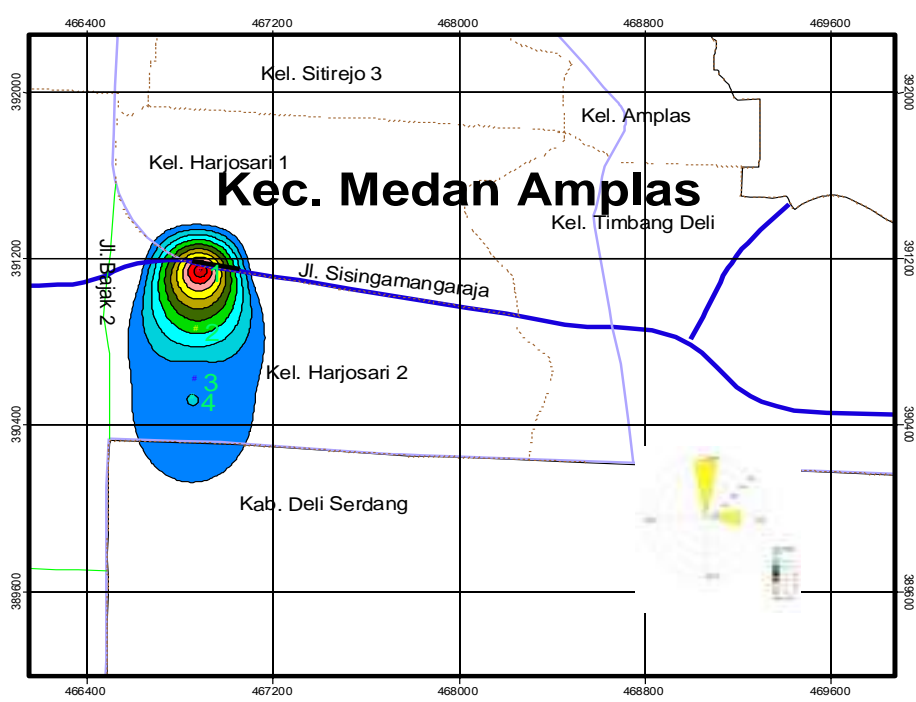

Gambar 10. Isoplet Konsentrasi Hasil Pengukuran Siang

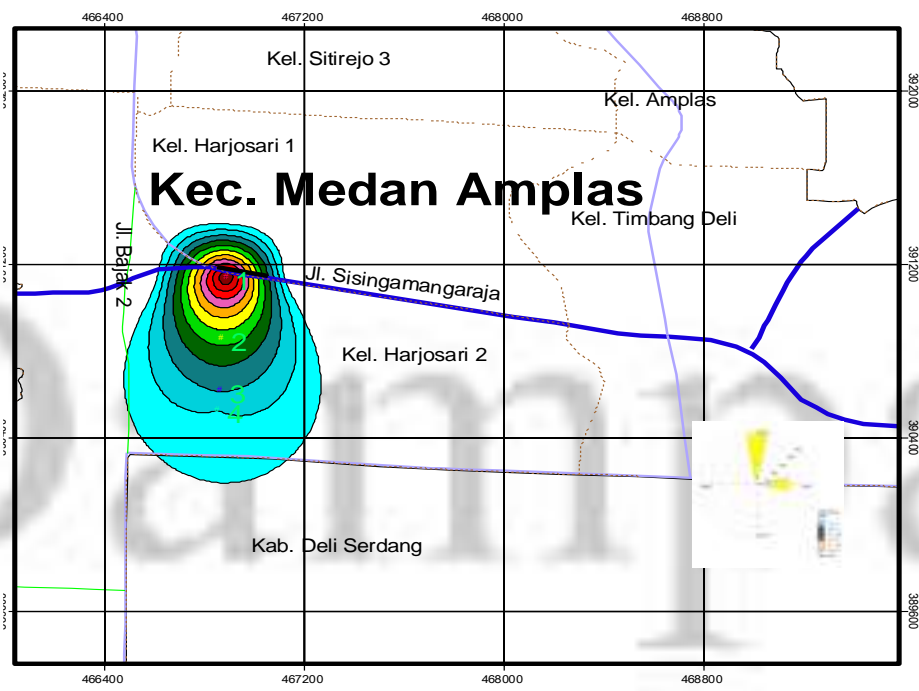

Gambar 11. Isoplet Konsentrasi Hasil Perhitungan pagi

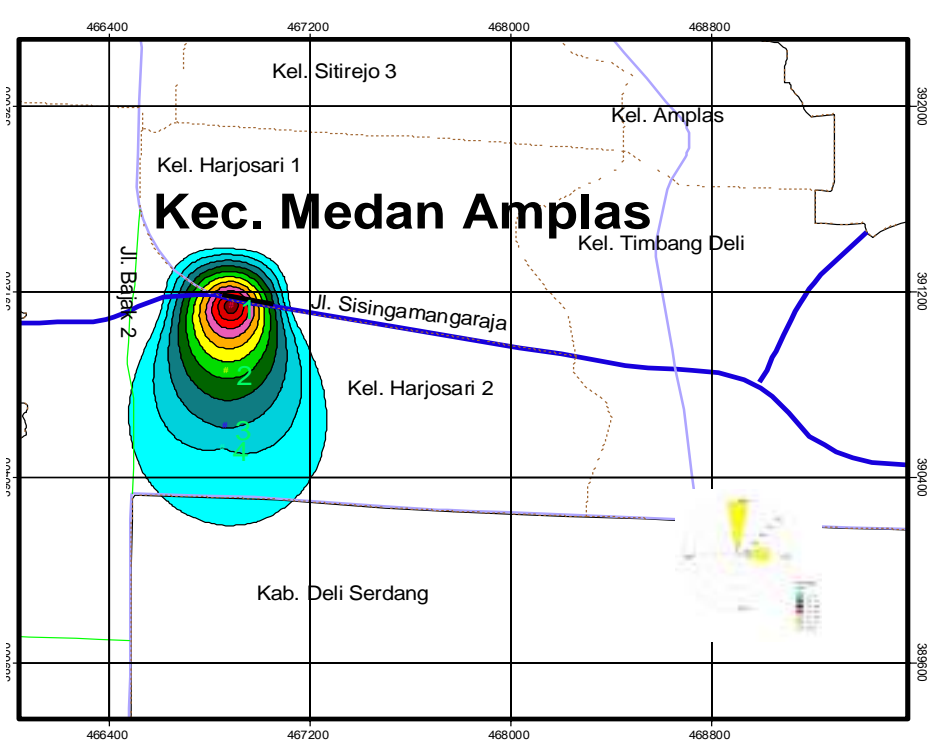

Gambar 12. Isoplet Konsentrasi Hasil Perhitungan Siang
Lokasi Sampling

1 Roadside

$2300 \mathrm{~m}$ dari jalan

$3500 \mathrm{~m}$ dari jalan

$4600 \mathrm{~m}$ dari jalan

Negmen jalan

batas kelurahan

jalan lokal primer

jalan arteri sekunder

jalan arteri primer

Konsentrasi (ug/Nm3)

15001-18000

$14001-15000$

$14001-15000$

$13001-14000$

$12001-13000$

$11001-12000$

$10001-11000$

$10001-11000$

$9001-10000$

$8001-9000$

$7001-8000$
Lokasi Sampling

1 Roadside

$2300 \mathrm{~m}$ dari jalan

$3500 \mathrm{~m}$ dari jalan

4600 m dari jalan

A segmen jalan

yang diamati

batas kelurahan

jalan lokal primer

jalan arteri sekund
Konsentrasi ( ug/Nm3)

$20000-21000$
$19001-20000$

$18001-19000$

$16001-18000$

$14001-16000$

$12001-14000$

$10001-12000$

$8001-10000$

$8001-10000$

$6001-8000$

$4001-6000$

$2001-4000$
$100-2000$

Lokasi Sampling

1 Roadside

$2300 \mathrm{~m}$ dari jalan

$3500 \mathrm{~m}$ dari jalan

$4600 \mathrm{~m}$ dari jalan

segmen jalan

yang diamati

batas kelurahan

jalan lokal primer

jalan arteri sekunder

Nalan arteri primer

Konsentrasi (ug/N m3)

$18001-19000$

$17001-18000$

$16001-17000$

$15001-16000$

$15001-16000$
$14001-15000$

$14001-15000$

$12001-14000$

$10001-12000$

$8001-10000$

$6001-8000$

$4001-6000$

$2001-4000$

100 - 2000 


\section{SIMPULAN}

Berdasarkan hasil pengamatan volume lalu lintas di Jalan Sisingamangaraja adalah 7.591 unit/jam saat pengamatan pagi dan 7.433 unit/jam saat pengamatan siang. Jumlah tersebut menyumbangkan laju emisi sebesar $49.171,7 \mu \mathrm{g} / \mathrm{m} . \mathrm{s}$ pada pagi hari dan pada siang hari sebesar 46.943,1 $\mu \mathrm{g} / \mathrm{m} . \mathrm{s}$.

Konsentrasi $\mathrm{CO}$ paling tinggi adalah pada tepi jalan (roadside) yaitu sebesar 20.340 $\mu \mathrm{g} / \mathrm{Nm}^{3}$ pada pagi hari dan $18.340 \mu \mathrm{g} / \mathrm{Nm}^{3}$ pada siang hari menurut perhitungan FLLS. Sedangkan berdasarkan pengukuran langsung konsentrasi maksimal sebesar $18.323 \mu \mathrm{g} / \mathrm{Nm}^{3}$ pada waktu pagi dan $17.177 \mu \mathrm{g} / \mathrm{Nm}^{3}$ pada waktu siang.

Perbandingan hasil pemodelan dan hasil pengukuran di lapangan dengan wilmott's index memiliki nilai $\mathrm{d}$ dan $\mathrm{R}$ mendekati 1 , NMSE <0,5. Hasil validasi memiliki keakuratan 16,5\%-17\% masih dalam kriteria pemodelan Gaussian (10\%-20\%).

\section{DAFTAR PUSTAKA}

Badan Standarisasi Nasional (BSN). 2011. SNI 7119.10.2011 Udara AmbienBagian 10: Cara Uji Kadar Karbon Monoksida (CO) Menggunakan Metode Non Dispersive Infra Red (NDIR). Indonesia.

Badan Pusat Statistik (BPS) Kota Medan. 2015. Medan Dalam Angka 2014. Medan.

Cooper, D dan Alley, F. 1994. Air Pollution Control. A Design Approach. Secound Edition. Waveland press Inc. USA.

Dinas Perhubungan (DISHUB) Kota Medan. 2016. Wahana Tata Nugraha 2015. Medan.

Hamid Taheri Shahraiyni, Davood Shahsavani, Saeed Sargazi, Majid Habibi-Nokhandan, 2015., Atmospheric Pollution Research6 $581-588$.

Handa PK and Tai DYH. 2005. Carbon monoxide poisoning: a five year review at Tan Tock Seng Hospital Singapore. Ann Acad Med Singapore 34(1): 611- 614.

Hassan H, Singh MP, Gribben RJ, Srivastava RM, Radojevic M, Latif A. 2006.
Application of Line Source Air Quality Model to The Study of Traffic Carbon Monoxide in Brunei Darussalam. ASEAN J. on Science and Technology for Development 17(1): 59-76.

Heist, D, Isakov V, Perry S, Snyder M, Venkatram A, Hood C, Stocker J, Carruthers D, Arunachalam S, Owen RC. 2013. Estimating near road pollutant dispersion : A model inter comparison, Transportation Research Part D 25(1): 93-105.

Hoek, G., Beelen, R., de Hoogh, K., Vienneau, D., Gulliver, J., Fischer, P.,Briggs, D., 2008. Atmospheric Environment42, 7561-7578.

Jerrett, M., Burnett, R.T., Ma, R.J., Pope, C.A., Krewski, D., Newbold, K.B ., Thurston, G., Shi, Y.L., Finkelstein, N., Calle, E.E., Thun, M.J., 2005.Epidemiology $16727-$ 736.

Kementrian Lingkungan Hidup (KLH). 1999. Peraturan Pemerintah Republik Indonesia Nomor 41 Tahun 1999 Tentang Pengendalian Pencemaran Udara. Indonesia.

Kementrian Lingkungan Hidup (KLH). 2013. Pedoman Teknis Penyusunan Inventarisasi Emisi Pencemar Udara di Perkotaan. Indonesia.

Nevers N. D. 2000. Air Pollution Control Engineering.secound Edition. McGraw-Hill. USA.

Paramitadevi, Y. V, Yuwono, A. S., and Widyarti, M. 2014. Simulation and Validation of Carbon Monoxide Dispersion Model In the Vicinity of Baranangsiang Toll Gates in Bogor. J. Appl. Environ. Biol. Sci., 4(6)110-117, 2014.

Pasquill, F. 1974. Atmospheric Diffusion, 2nded. Ellis Horwood Ltd. Chichester. England. 365 - 380 pp.

Peavy, H.S, Rowe, D.R, dan Tchobangolous,G. 1985. Environmental Engineering. McGraw-Hill. USA.

Schenelle, K.B. and Dey P. 2003. Atmospheric Dispersion Modeling Compliance Guide. New York (US): Mc Graw-Hill.

Soedomo, M. 1999. Kumpulan Karya Ilmiah Pencemaran Udara. ITB. Bandung. 
Supriyadi, E. 2009. Penerapan Model Finite Length Line Source Untuk Menduga Konsentrasi Polutan Dari Sumber Garis (Studi Kasus: Jl. M.H. Thamrin, Dki Jakarta). Skripsi. Departemen Geofisika Dan Meteorologi Fakultas Matematika Dan Ilmu Pengetahuan Alam Institut Pertanian Bogor. Bogor.

Suryati, I and Khair, H. 2016. Mapping Air Quality Index of Carbon Monoxide $(\mathrm{CO})$ in Medan City. Prosiding Seminar AASEC.UPI

Wardhana, W. A. 2004. Dampak Pencemaran Lingkungan. Penerbit ANDI. Yogyakarta.

Willmott C, Robeson SM, Matsuura K. 2012. A Refined Index of Model Performance. International Journal of Climatology 32(13): 2088-2094.doi: 10.1002/joc.2419 